\title{
Recombinant hirudin enhances cardiac output and decreases systemic vascular resistance during reperfusion after cardiopulmonary bypass in a porcine model
}

Mikko Jormalainen, $\mathrm{MD}^{\mathrm{a}}$

Antti E. Vento, MD, PhD

Ulla Wartiovaara-Kautto, MD, $\mathrm{PhD}^{\mathrm{b}}$

Raili Suojaranta-Ylinen, $M D, P^{\circ}{ }^{c}$

O. Juhani Rämö, MD, $P h D^{a}$

Jari Petäjä, MD, $P h D^{\mathrm{d}}$
From the Departments of Cardiothoracic Surgery, ${ }^{\mathrm{a}}$ Clinical Chemistry, ${ }^{\mathrm{b}}$ and Anesthesiology and Intensive Care Medicine, ${ }^{c}$ Helsinki University Central Hospital, Helsinki, Finland, and Department of Pediatrics, ${ }^{\mathrm{d}}$ Jorvi Hospital, and Hospital for Children and Adolescents, Helsinki University Central Hospital, Helsinki, Finland.

This work was supported by Helsinki University Hospital Research Fund and by grants from the Foundation for Pediatric Research, the Sigrid Juselius Foundation, and Finnish Society of Angiology.

Received for publication April 23, 2003; revisions received Oct 23, 2003; accepted for publication Nov 4, 2003.

Address for reprints: Mikko Jormalainen, MD, Department of Cardiothoracic Surgery, University of Helsinki, Haartmaninkatu 4, FIN-00290 Helsinki, Finland (E-mail: mikko.jormalainen@hus.fi).

J Thorac Cardiovasc Surg 2004;128:189-96 $0022-5223 / \$ 30.00$

Copyright ( $\odot 2003$ by The American Association for Thoracic Surgery

doi:10.1016/j.jtcvs.2003.11.058
Objective: Cardiopulmonary bypass and surgical stress are accompanied by a systemic inflammatory response and activation of coagulation. Thrombin forms fibrin and activates platelets and neutrophils. Consequently, disseminated microthrombosis might increase capillary vascular resistance and thus impair reperfusion. We hypothesized that recombinant hirudin, a direct inhibitor of thrombin, could attenuate coagulation and enhance microvascular flow during reperfusion.

Methods: Twenty pigs undergoing 60 minutes of aortic clamping and 75 minutes of normothermic perfusion were randomized in a blinded setting to receive an intravenous bolus of recombinant hirudin $(10 \mathrm{mg}, 0.4 \mathrm{mg} / \mathrm{kg} ; \mathrm{n}=10)$ or placebo $(\mathrm{n}=$ 10) 15 minutes before aortic declamping and then continued with an intravenous 135 -minute infusion of recombinant hirudin $(3.75 \mathrm{mg} / \mathrm{h}, 0.15 \mathrm{mg} / \mathrm{kg})$ or placebo. Thrombin-antithrombin complexes, activated clotting times, and several hemodynamic parameters were measured before cardiopulmonary bypass, after weaning from cardiopulmonary bypass, and at 30, 60, 90, and 120 minutes after aortic declamping. Intramucosal $\mathrm{pH}$ and $\mathrm{PCO}_{2}$ were measured from the luminal surface of ileum simultaneously with arterial gas analysis at 30-minute intervals.

Results: Recombinant hirudin inhibited thrombin formation after aortic declamping; at 120 minutes, thrombin-antithrombin complexes levels $(\mu \mathrm{g} / \mathrm{L}$, mean $\pm \mathrm{SD})$ were $75 \pm 21$ and $29 \pm 44(P<.001)$ for placebo and pigs receiving recombinant hirudin, respectively. When compared with the placebo group, pigs receiving recombinant hirudin showed significantly higher stroke volume, cardiac output, and lower systemic vascular resistance at 60 and 90 minutes after aortic declamping $(P$ $<.05)$. Based on arteriomucosal $\mathrm{PCO}_{2}$ and $\mathrm{pH}$ differences, progressive worsening of intestinal microcirculatory perfusion occurred in the placebo group but not in the recombinant hirudin group.

Conclusion: Infusion of thrombin inhibitor recombinant hirudin during reperfusion was associated with attenuated postischemia left ventricular dysfunction and decreased vascular resistance. Consequently microvascular flow was improved during ischemia-reperfusion injury. Control of thrombin formation during reperfusion may be a feasible approach to improve oxygen delivery to reperfused vascular beds. 


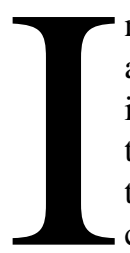

$\mathrm{n}$ cardiac surgery cardiopulmonary bypass (CPB) and surgical stress are accompanied by a systemic inflammatory response, ${ }^{1-3}$ which results in activation and interaction of several humoral amplification systems. Aortic clamping causes global myocardial ischemia but $\mathrm{CPB}$ can also cause hypoperfusion of various organs. Although CPB maintains splanchnic circulation, low pumping pressure, nonpulsatile perfusion, and hypothermia lead to splanchnic hypoperfusion and ischemia. ${ }^{4-6}$ Restoration of myocardial blood flow and normal circulation conditions to hypoperfused areas results in ischemia-reperfusion injury.

Ischemia-reperfusion injury is initiated by overlapping cascades of inflammatory mediators at systemic and local levels causing an acute inflammatory response and activation of coagulation in postischemic tissues. ${ }^{7-10}$ Postischemic endothelium becomes activated and expresses proinflammatory and procoagulatory properties contributing to the noreflow phenomenon by promoting endothelial edema, neutrophil and platelet plugging, microthrombosis, and increased vasomotor tone. ${ }^{11}$ Inflammatory mediators ${ }^{12}$ and also surgical trauma ${ }^{13,14}$ activate endothelium to express tissue factor, thus promoting generation of thrombin throughout the intravascular space but especially in the reperfused tissues. ${ }^{9,10}$ Thrombin, the key enzyme of coagulation, plays a central role between inflammatory and coagulation systems. Cytokines enhance thrombin formation and thrombin activates platelets, endothelium, and leukocytes and forms fibrin from fibrinogen. ${ }^{15,16}$ All these events may potentially promote microthrombosis, potentiate reperfusion-induced capillary occlusion, and lead to ischemic organ dysfunction.

Hirudin is a selective and effective inhibitor of thrombin. In previous studies of inflammation-associated coagulopathy, recombinant hirudin (r-hirudin; lepirudin) blunted endotoxin-induced activation of coagulation in humans ${ }^{17}$ and attenuated liver injury in rats. ${ }^{18}$ In rabbits, r-hirudin significantly reduced renal fibrin deposits in a model of endotoxin-induced disseminated intravascular coagulation. ${ }^{19}$ Effects of hirudin on CPB-induced ischemia-reperfusion model have not been studied. We wanted to test in a porcine model whether r-hirudin could attenuate reperfusion-induced formation of thrombin and whether this inhibition might have any effect on general hemodynamics or intestinal microcirculation.

\section{Materials and Methods Animals}

Twenty pigs of either sex weighing approximately $26 \mathrm{~kg}$ were used as experimental animals. They were allowed at least 3 days of in-house acclimatization with ad libitum access to standard laboratory food and water. All animals received humane care in compliance with the "Principles of Laboratory Animal Care" formulated by the National Society for Medical Research and the "Guide for the Care and Use of Laboratory Animals" prepared by the National Academy of Sciences and published by the National Institutes of Health (NIH Publication No. 86-23, revised 1985). All experiments were approved by the Local Ethical Committee of Helsinki University Central Hospital.

\section{Anesthesia}

General anesthesia was induced by giving ketamine hydrochloride $500 \mathrm{mg}$ intramuscularly. Two milliliters of pentobarbital sodium, 3 $\mathrm{mL}$ of pancuronium bromide, and $0.1 \mathrm{mg}$ of fentanyl citrate were given intravenously. The pigs were intubated and ventilated with Siemens Servo Ventilator 900 C (Siemens-Elema AB, Solna, Sweden) under continuous electrocardiogram (ECG) monitoring (S/5 Anesthesia Monitor, Datex-Ohmeda, Helsinki, Finland). General anesthesia was maintained with continuous pancuronium promide $(0.25 \mathrm{mg} / \mathrm{kg} / \mathrm{h})$, pentobarbital $(5 \mathrm{mg} / \mathrm{kg} / \mathrm{h})$, and fentanyl $(0.015 \mathrm{mg} / \mathrm{kg} / \mathrm{h})$ infusions.

\section{Operative Technique}

The left femoral artery and vein were catheterized. Heparin (500 $\mathrm{IU} / \mathrm{kg}$ ) was given just after the vein was catheterized. Arterial blood pressure was continuously monitored and the femoral vein was used for intravenous anesthesia. The right femoral vein was catheterized for infusion of drug or placebo. A small midline laparotomy was performed and intestinal air-automated $14 \mathrm{~F}$ tonometry catheter (Tonometrics Catheter, Datex-Ohmeda) was inserted into the lumen of ileum $50 \mathrm{~cm}$ proximal from the ileocecal junction and secured with a 5-0 polypropylene purse-string suture. A midline sternotomy was performed. After sternotomy, the pulmonary artery was catheterized with a pediatric 5F Swan-Ganz catheter (Baxter Health Corporation, Santa Ana, Calif) via superior caval vein. Venous drainage was provided by a cannula in the right atrium and an aortic perfusion catheter was placed in the aorta. The left ventricle was catheterized through the apex of the heart for pressure measurements. After the initial dose of heparin activated coagulation time (ACT) was measured before CPB and at 30minute intervals until 90 minutes post-CPB and an additional dose (100-200 IU/kg) of heparin was given during perfusion whenever ACT was below 400 seconds. As a result, 4 animals in the placebo group and 3 animals in the r-hirudin group received additional doses of heparin during CPB. Protamine was not given.

A Gambro 2-roller pump (Gambro, Lund, Sweden) and a D 705 miniflow pediatric hollow fiber oxygenator (Dideco, Mirandola, Italy) were used in all experiments. CPB circuit was primed with $1000 \mathrm{~mL}$ Ringersteril (Baxter; Vantaa, Finland) and $5000 \mathrm{IU}$ of heparin. Hemodynamic, biochemical, and intestinal tonometric baseline values were determined before normothermic perfusion ( 2 $\mathrm{L} / \mathrm{min}$ ) was started. The oxygenator was heated with a heat exchanger (Heater, Amer Group LTD, Tekamer, Helsinki, Finland), and temperature was kept at $+37.2^{\circ} \mathrm{C}$. After the initiation of perfusion, the aorta was clamped and the heart was arrested with $+4^{\circ} \mathrm{C}(15 \mathrm{~mL} / \mathrm{kg})$ Plegisol (Abbot Laboratories, North Chicago, Ill). Myocardial temperature was continuously monitored and a pericardial insulation pad was used during the crossclamping time.

Cardioplegic solution $(2 \mathrm{~mL} / \mathrm{kg}$ ) was added every 15 minutes and if ventricular fibrillation occurred. Arterial acid-base balance was monitored during operation at 30-minute intervals (ABL System 615, Radiometer Medical A/S, Copenhagen, Denmark). 


\section{Study Setting}

In a randomized and blinded manner an intravenous bolus (10 mg, $0.4 \mathrm{mg} / \mathrm{kg}$ ) of lepirudin (Refludan, Aventis Behring, Marburg, Germany, and called from hereon "r-hirudin"; $n=10$ ) or placebo (20 mL NaCl; $\mathrm{n}=10$ ) was given 15 minutes before aortic clamp was released and then continued with a 135-minute intravenous infusion of r-hirudin $(3.75 \mathrm{mg}, 0.15 \mathrm{mg} / \mathrm{kg})$ or placebo.

Aortic clamping was released after 1 hour. After clamp release, ventilation was begun at 7 minutes and the heart was supported by continuing $\mathrm{CPB}$ for 15 minutes. If ventricular fibrillation was present after 4 minutes, defibrillation was used repeatedly in 1-minute intervals until hemodynamically effective sinus rhythm was achieved.

Heart rate (HR), ECG, arterial blood pressure (AP), central venous pressure (CVP), and pulmonary artery pressure were monitored continuously. CVP was standardized before each measurement of the hemodynamic profile. Cardiac output (CO) was obtained simultaneously with HR, pulmonary arterial diastolic pressure (PADP), pulmonary capillary wedge pressure (PCWP), AP, left ventricular pressure (LVP), and systemic vascular resistance (SVR) measurements. Inotropic medication was not used. Blood from mediastinal and pleural spaces was collected and returned into the CPB system. Blood from the abdomen was collected into a separate reservoir. Experimental animals were killed during anesthesia by exsanguination after a surveillance period of 105 minutes after cessation of CPB.

\section{Hemodynamic Profile}

Hemodynamic measurements were obtained before perfusion and after weaning from $\mathrm{CPB}$ and at 15, 30, 60, 90, and 120 minutes after clamp release. ECG, AP, PADP, CVP, and LVP were monitored continuously. $\mathrm{CO}$ measurements were obtained using a thermodilution method. ${ }^{20} \mathrm{~A}$ thermodilution probe was directed into the main pulmonary artery and connected to a cardiac computer (S/5 Anesthesia Monitor, Datex-Ohmeda). The recorded value was taken as an average from 3 acceptable measurements. $\mathrm{SVR}$ was calculated using the equation $\mathrm{SVR}=$ (mean arterial pressure - CVP) $\cdot 80 / C O$.

\section{Blood Samples}

Blood samples from the catheter inserted through the femoral vein into the inferior caval vein were obtained before perfusion, just before aortic declamping, and at 5, 10, 30, and 120 minutes after aortic clamp was released. Thrombin antithrombin complexes (TAT) were measured using commercial reagents (Enzygnost TAT micro, Dade Behring, Liederbach, Germany). ACT was measured from blood samples obtained from the femoral artery using a 2-channel Automated Coagulation Timer (Medtronic Blood Management, Parker, Colo).

\section{Tonometric and Blood Gas Measurements}

An air-automated tonometry catheter inserted into the ileum included a semipermeable silicone balloon at the distal end of the catheter. Four milliliters of room air was pumped into the silicon balloon. $\mathrm{CO}_{2}$ freely equilibrated between the intestinal mucosa, intestinal lumen, and the balloon. The proximal end of the catheter was connected to a tonometry module (S/5 Tonometry Module,
Datex-Ohmeda). The system drew a gas sample from the balloon and intestinal $\mathrm{PCO}_{2}\left(\mathrm{PiCO}_{2}\right)$ was automatically measured every 10 minutes. Intramucosal $\mathrm{pH}(\mathrm{pHi})$ was automatically calculated by the monitor from $\mathrm{PaCO}_{2}$ and $\mathrm{pHa}$ values obtained from arterial gas analysis, entered by user, and $\mathrm{PiCO}_{2}$ measured. pHi was calculated by using the equation $\mathrm{pHi}=\mathrm{pHa}+\log _{10} \cdot\left(\mathrm{PaCO}_{2} / \mathrm{PiCO}_{2}\right)$. Tonometric and arterial acid-base values were obtained before perfusion (0), after 30 minutes of perfusion, just before aortic declamping, and at 30,60, 90, and 120 minutes after aortic clamp release.

Bleeding during study drug infusion from the laparotomy wound and from the intestinal biopsy sites was measured by collecting blood from abdomen into a separate reservoir. Blood from the mediastinal and pleural spaces was also measured.

\section{Statistical Methods}

Differences between the 2 experimental groups in hemodynamic, tonometric, and blood gas measurements were statistically evaluated using the repeated measure analysis of covariance model, which included the baseline value as a covariant. Baseline values between the 2 experimental groups were compared with 2-tailed Student $t$ test. Data are presented as mean \pm standard deviation (SD).

\section{Results}

In the placebo group 1 animal died in the beginning of the experiment because of a rupture in the aortic root. One animal died in the placebo group and 1 in the r-hirudin group at 30 minutes after aortic declamping and 2 in the r-hirudin group at 90 minutes after aortic declamping because of a hemodynamic collapse. Eight animals in the placebo group and 7 animals in the hirudin group survived until the end of surveillance period.

There were no differences between the placebo and rhirudin groups in the time $(6.8 \pm 2.6$ minutes vs $6.2 \pm 3.0$ minutes, $P=.66$ ) needed to achieve regular hemodynamically effective rhythm nor in the number of defibrillations needed.

\section{Blood Samples}

R-hirudin effectively inhibited coagulation as assessed by ACT. Fifteen minutes after the bolus of r-hirudin ACT was significantly prolonged in the r-hirudin group compared with the placebo group $(834 \pm 231$ seconds vs $515 \pm 260$ seconds, $P=.008$ ). Also 15 minutes after weaning from bypass ACT was significantly longer in the r-hirudin group when compared with the placebo group (658 \pm 335 seconds vs $274 \pm 75$ seconds, $P=.005)$. Plasma levels of TAT increased in both groups during CPB (Figure 1). Notably, in the placebo group there was a pronounced reperfusionassociated increase in TAT levels from 30 to 120 minutes after aortic declamping and the difference between the experimental groups was significant at 120 minutes (placebo $75.4 \pm 15.6 \mu \mathrm{g} / \mathrm{L}$ vs r-hirudin $28.9 \pm 7.1 \mu \mathrm{g} / \mathrm{L}, P<$ $.001)$ after aortic declamping (Figure 1). 


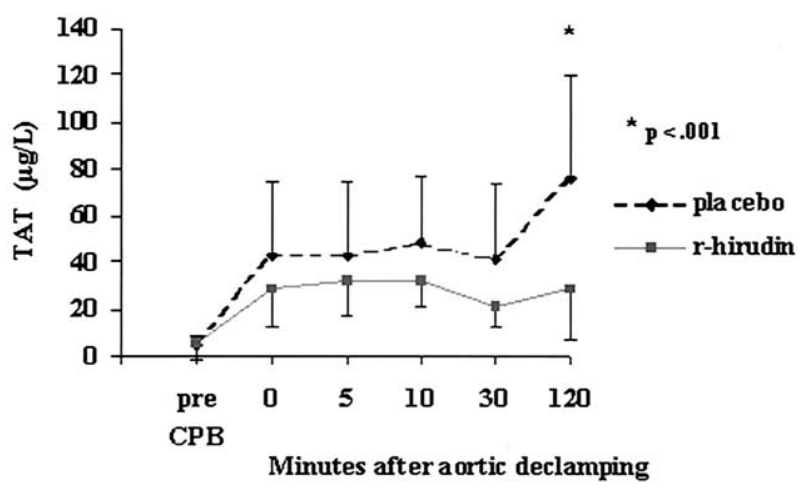

Figure 1. The effect of r-hirudin on thrombin-antithrombin (TAT) complexes during CPB and during reperfusion. Both experimental groups consisted of 10 animals. $P$ value for comparison between the 2 experimental groups was calculated with analysis of covariance. Values are given as mean \pm SD. Pre CPB, Before CPB; 0 , just before aortic declamping.

\section{Hemodynamics}

Hemodynamic parameters are presented in Table 1 and in Figure 2. HR increased slowly but progressively in both groups toward the end of the surveillance period (Table 1). $\mathrm{CO}$ dropped similarly in both groups but the pigs receiving r-hirudin showed significantly higher stroke volume (SV) and $\mathrm{CO}$ at 60 minutes and at 90 minutes after aortic declamping (Figure 2). Importantly, in the r-hirudin group $\mathrm{SV}$ and CO showed recovery toward the preperfusion situation while in the controls no such trend was observed (Figure 2). In the placebo group SVR increased markedly during reperfusion (Figure 2). This reperfusion-induced increase in SVR was effectively abolished in the r-hirudin group (Figure 2). The difference between the r-hirudin and placebo groups reached statistical significance at 60 and 90 minutes after aortic declamping (Figure 2). Pulmonary vascular resistance (PVR) was recorded only for some of the animals. PVR showed a qualitatively similar pattern of changes as SVR. PVR was significantly higher in the placebo group at 60 minutes after aortic declamping $(990 \pm$ 337 dyne $\cdot \mathrm{s} / \mathrm{cm}^{5}, \mathrm{n}=4$, vs $526 \pm 191$ dyne $\cdot \mathrm{s} / \mathrm{cm}^{5}, \mathrm{n}=$ $8 ; P=.01)$.

In both groups, after CPB there were lower systolic, mean, and diastolic arterial pressures compared with values before CPB (Table 1). Arterial pressures slowly returned toward baseline values thereafter but no significant difference was seen between the 2 groups. In LVP a similar trend was seen but there was no significant difference between the 2 groups (Table 1).

In the r-hirudin group PADP was higher before CPB, mainly because 2 animals had exceptionally high $(30 \mathrm{~mm}$ $\mathrm{Hg}$ ) values. During the follow-up PADP increased in both groups but no significant difference was observed between the 2 groups.

\section{Intestinal Tonometry and Blood Gas Analysis}

Data on intestinal tonometry and blood gas analysis are shown in Figure 3 and in Table 2. Reperfusion was associated with progressive local mucosal hypoperfusion in both groups as evidenced by significantly increased $\mathrm{PiCO}_{2}$ and decreased intestinal $\mathrm{pH}$ values in both groups. In the placebo group but not in the r-hirudin group, there were changes in curve trends of $\mathrm{PiCO}_{2}$ and pHi at 30 minutes after aortic declamping but this did not result in significant intergroup differences (Figure 3).

Progressive systemic acidosis observed in both groups was not due to inefficient oxygenation as arterial $\mathrm{O}_{2}$ increased during $\mathrm{CPB}$ but returned to and remained at near pre-CPB values after CPB in both groups (Table 2).

To evaluate local microcirculatory perfusion in intestinal mucosa, the gaps between $\mathrm{pHa}$ and $\mathrm{pHi}$ and $\mathrm{PaCO}_{2}$ and $\mathrm{PiCO}_{2}$ were calculated (Figure 3). Progressive intestinal hypercapnia and acidosis developed between 30 and 120 minutes after the clamp release in the placebo group. Remarkably, no such local increments in acidosis or hypercapnia were observed in the r-hirudin group. The rise in $\mathrm{P}(\mathrm{i}-\mathrm{a}) \mathrm{CO}_{2}$ from 30 to 120 minutes postreperfusion was $5.82 \pm 6.65 \mathrm{kPa}$ and $0.79 \pm 1.7 \mathrm{kPa}$ in the placebo and r-hirudin groups, respectively $(P=.044)$. Corresponding values for $\mathrm{pH}(\mathrm{a}-\mathrm{i})$ were $0.21 \pm 0.21$ versus $0.018 \pm 0.08(P=.024)$.

Hemoglobin significantly decreased in both groups over time $(P<.001)$ and it was significantly lower in r-hirudin group at 90 minutes after aortic declamping (Table 2). Enhanced bleeding was seen in the r-hirudin group (1753 \pm $671 \mathrm{~mL}$ vs $850 \pm 376 \mathrm{~mL}, P=.007)$. Bleeding from mediastinal and pleural spaces, which was returned to CPB circuit, was $500 \pm 236 \mathrm{~mL}$ in the placebo group and 1200 $\pm 615 \mathrm{~mL}$ in the r-hirudin group $(P=.011)$. However, only blood collected from abdominal cavity into a separate reservoir, which was not returned to the animal, presented net blood loss. This was not significantly different between the 2 groups $(530 \pm 296 \mathrm{~mL}$ vs $325 \pm 223 \mathrm{~mL}, P=.126$, r-hirudin vs controls, respectively).

\section{Discussion}

This study tested the hypothesis that direct inhibition of thrombin could attenuate adverse functional consequences of ischemia-reperfusion injury. Thrombin is an enzyme with pleiotrophic effects on cells, including platelets, leukocytes, endothelial cells, and cardiomyocytes, as well as on several circulating coagulation factors. On the other hand, clinically available anticoagulants, including heparin, possess nonthrombin-related pharmacological effects on plasmatic clotting factors and circulating cells. This makes it most difficult to study potential pathophysiological significance of thrombin per se during clinical ischemia-reperfusion injury. Therefore, we chose to study r-hirudin, the most thrombinspecific clinical anticoagulant that is not known to possess 
TABLE 1. Hemodynamic data

\begin{tabular}{|c|c|c|c|c|c|c|}
\hline \multirow[b]{2}{*}{ Parameter } & \multicolumn{6}{|c|}{ Time after aortic declamping } \\
\hline & Pre-CPB & $\begin{array}{c}15 \\
\text { minutes }\end{array}$ & $\begin{array}{c}30 \\
\text { minutes }\end{array}$ & $\begin{array}{c}60 \\
\text { minutes }\end{array}$ & $\begin{array}{c}90 \\
\text { minutes }\end{array}$ & $\begin{array}{c}120 \\
\text { minutes }\end{array}$ \\
\hline \multicolumn{7}{|c|}{ HR (beats/min) } \\
\hline Hirudin & $134 \pm 20$ & $136 \pm 16$ & $136 \pm 14$ & $136 \pm 15$ & $143 \pm 20$ & $156 \pm 26$ \\
\hline Placebo & $118 \pm 13$ & $136 \pm 27$ & $151 \pm 20$ & $151 \pm 18$ & $155 \pm 25$ & $153 \pm 22$ \\
\hline$P$ value & .06 & $>.2$ & .06 & .08 & .14 & $>.2$ \\
\hline \multicolumn{7}{|c|}{ SAP $(\mathrm{mm} \mathrm{Hg})$} \\
\hline Hirudin & $120 \pm 18$ & $100 \pm 15$ & $112 \pm 11$ & $121 \pm 21$ & $125 \pm 29$ & $134 \pm 20$ \\
\hline Placebo & $117 \pm 15$ & $96 \pm 25$ & $110 \pm 23$ & $113 \pm 33$ & $123 \pm 24$ & $115 \pm 14$ \\
\hline$P$ value & $>.2$ & $>.2$ & $>.2$ & $>.2$ & $>.2$ & .20 \\
\hline \multicolumn{7}{|c|}{$\mathrm{MAP}(\mathrm{mm} \mathrm{Hg})$} \\
\hline Hirudin & $83 \pm 13$ & $58 \pm 10$ & $64 \pm 17$ & $70 \pm 25$ & $70 \pm 27$ & $76 \pm 19$ \\
\hline Placebo & $80 \pm 13$ & $55 \pm 8$ & $64 \pm 9$ & $67 \pm 19$ & $74 \pm 19$ & $66 \pm 17$ \\
\hline$P$ value & $>.2$ & $>.2$ & $>.2$ & $>.2$ & $>.2$ & $>.2$ \\
\hline \multicolumn{7}{|c|}{ PAPD $(\mathrm{mm} \mathrm{Hg})$} \\
\hline Hirudin & $18 \pm 10$ & $19 \pm 5$ & $20 \pm 8$ & $21 \pm 7$ & $24 \pm 8$ & $26 \pm 5$ \\
\hline Placebo & $12 \pm 4$ & $17 \pm 6$ & $17 \pm 6$ & $23 \pm 7$ & $25 \pm 5$ & $25 \pm 6$ \\
\hline$P$ value & .11 & $>.2$ & $>.2$ & $>.2$ & $>.2$ & $>.2$ \\
\hline \multicolumn{7}{|c|}{$\operatorname{LVP}(\mathrm{mm} \mathrm{Hg})$} \\
\hline Hirudin & $131 \pm 20$ & $114 \pm 16$ & $124 \pm 19$ & $124 \pm 29$ & $127 \pm 39$ & $133 \pm 28$ \\
\hline Placebo & $131 \pm 13$ & $103 \pm 27$ & $109 \pm 23$ & $108 \pm 39$ & $122 \pm 24$ & $117 \pm 21$ \\
\hline$P$ value & $>.2$ & $>.2$ & $>.2$ & .14 & $>.2$ & $>.2$ \\
\hline \multicolumn{7}{|c|}{ PCWP (mm Hg) } \\
\hline Hirudin & $5 \pm 2$ & $5 \pm 1$ & $5 \pm 2$ & $6 \pm 2$ & $5 \pm 2$ & $5 \pm 1$ \\
\hline Placebo & $4 \pm 1$ & $5 \pm 2$ & $4 \pm 2$ & $5 \pm 2$ & $5 \pm 2$ & $5 \pm 2$ \\
\hline$P$ value & $>.2$ & $>.2$ & $>.2$ & $>.2$ & .11 & .02 \\
\hline
\end{tabular}

$H R$, Heart rate; $S A P$, systemic arterial pressure; $M A P$, mean arterial pressure; $P A P D$, pulmonary artery diastolic pressure; $L V P$, left ventricular pressure; $P C W P$, pulmonary capillary wedge pressure; Pre-CPB, before cardiopulmonary bypass ( $P$ value was calculated with Student $t$ test).

$P$ value for comparison between the experimental groups was calculated with analysis of covariance.

significant unspecific hemodynamic effects. However, the complex interacting cellular and enzymatic mechanisms of ischemia-reperfusion injury may prevent interpreting the current hemodynamic results as being exclusively due to isolated thrombin inhibition, leaving open a possibility of yet unknown non-thrombin-related effects of r-hirudin. Bearing these reservations in mind, we feel the current approach to be a feasible effort to better understand the potential pathophysiological significance of thrombin activity after CPB.

Transient left ventricular dysfunction due to myocardial reperfusion injury is a significant and common problem after cardiac surgery. ${ }^{21}$ In the control group SV decreased by $44 \%$ after CPB and showed no improvement thereafter. In remarkable contrast, during early reperfusion animals receiving r-hirudin could regenerate a significant part of the lost left ventricular function. At 60 minutes after clamp release, animals receiving r-hirudin showed $86 \%$ of the preperfusion SV while the corresponding average figure for control animals was $49 \%$. The mechanisms by which thrombin inhibition may improve ventricular function remain to be determined. However, besides possible attenuation of microcirculatory occlusions by r-hirudin, the current data from the in vivo setting offer logical support to the previous in vitro demonstration that thrombin may directly inhibit myocyte contractile function. ${ }^{22,23}$ Thus, improved thrombin inhibition may be a feasible approach to reduce myocardial reperfusion injury.

Effects of isolated thrombin inhibition on reperfusioninduced changes on peripheral microcirculation after CPB have not been reported previously. In a feline model of ischemia-reperfusion injury of mesenteric vascular bed, infusion of antithrombin abolished the postischemia increase in vascular resistance that was observed in control animals. ${ }^{24}$ However, as antithrombin may exhibit specific antiinflammatory properties distinct from its inhibiting effect on thrombin, ${ }^{24,25}$ the contribution of thrombin inhibition to the improved microvascular flow remained undetermined. In the current study, infusion of r-hirudin prevented the increase in SVR after CPB that was observed in the control group. Accordingly, reperfusion seems, indeed, to be associated with progressive but transient increase in SVR. ${ }^{24}$ More importantly, the current data demonstrate that this phenomenon could effectively be abolished by thrombin inhibition. This effect could theoretically either improve or worsen peripheral circulation depending on the compensatory capacity of the heart. Therefore, considering therapeutic applications of thrombin inhibition during reperfusion, it 

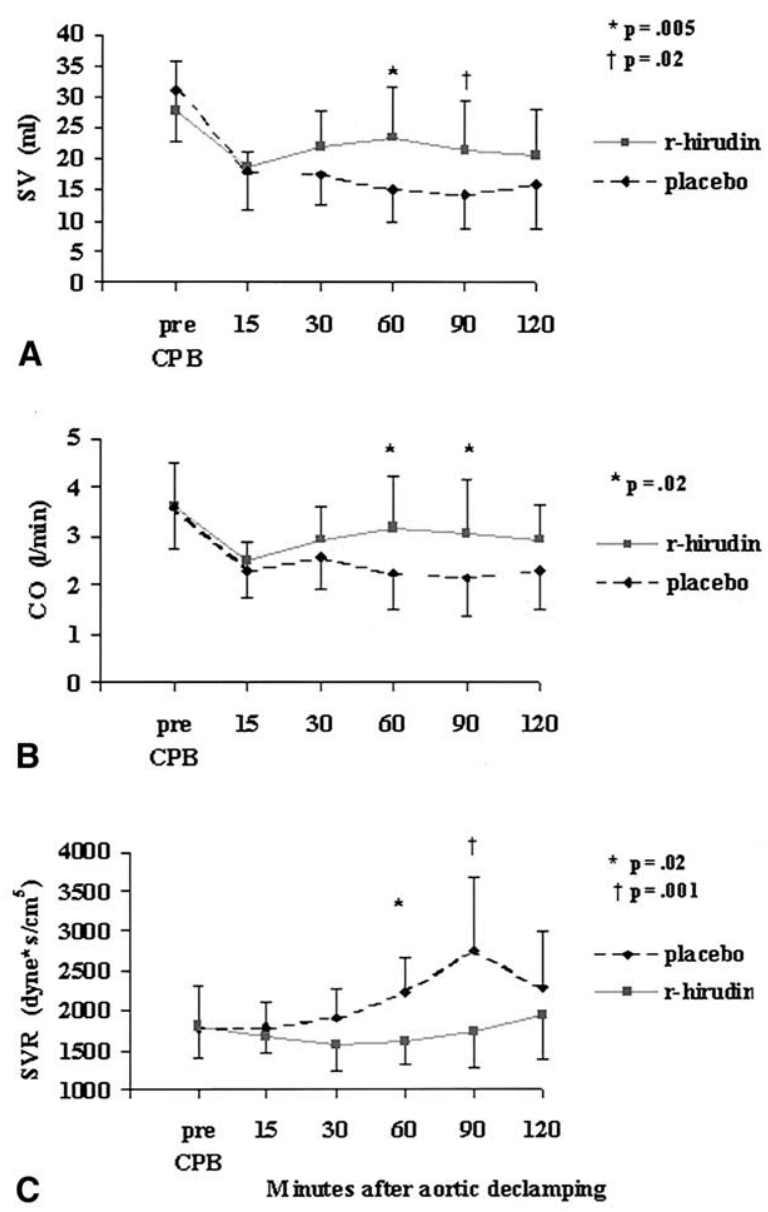

Figure 2. The effect of r-hirudin on stroke volume (SV) (A), cardiac output (CO) (B), and systemic vascular resistance (SVR) (C) during $\mathrm{CPB}$ and during reperfusion. $P$ value for comparison between the $\mathbf{2}$ experimental groups was calculated with analysis of covariance. Values are given as mean $\pm \mathrm{SD}$. Pre $C P B$, Before CPB.

is encouraging that instead of possible systemic hypotension, myocardium was able to generate better $\mathrm{SV}$ and $\mathrm{CO}$ and so compensate peripheral potentially hypotension-promoting effects of r-hirudin. Thus, a net effect most probably was enhanced flow in various microcirculatory vascular beds.

CPB results in reduced intestinal intramucosal blood flow, mucosal acidosis, and dysfunction. ${ }^{4,5,26,27}$ In animal studies jejunal and ileal mucosal flow decreased by $38 \%$ to $73 \%$ during CPB. Ischemia-reperfusion injury in the intestine is characterized by inflammation and capillary plugging. ${ }^{28}$ In the current study, intestinal tonometry indirectly assessing tissue oxygenation ${ }^{29}$ showed progressive intramucosal acidosis during and after $\mathrm{CPB}$, indicating reduced microvascular blood flow to the intestinal mucosa. However, because of several confounding factors, quantitating
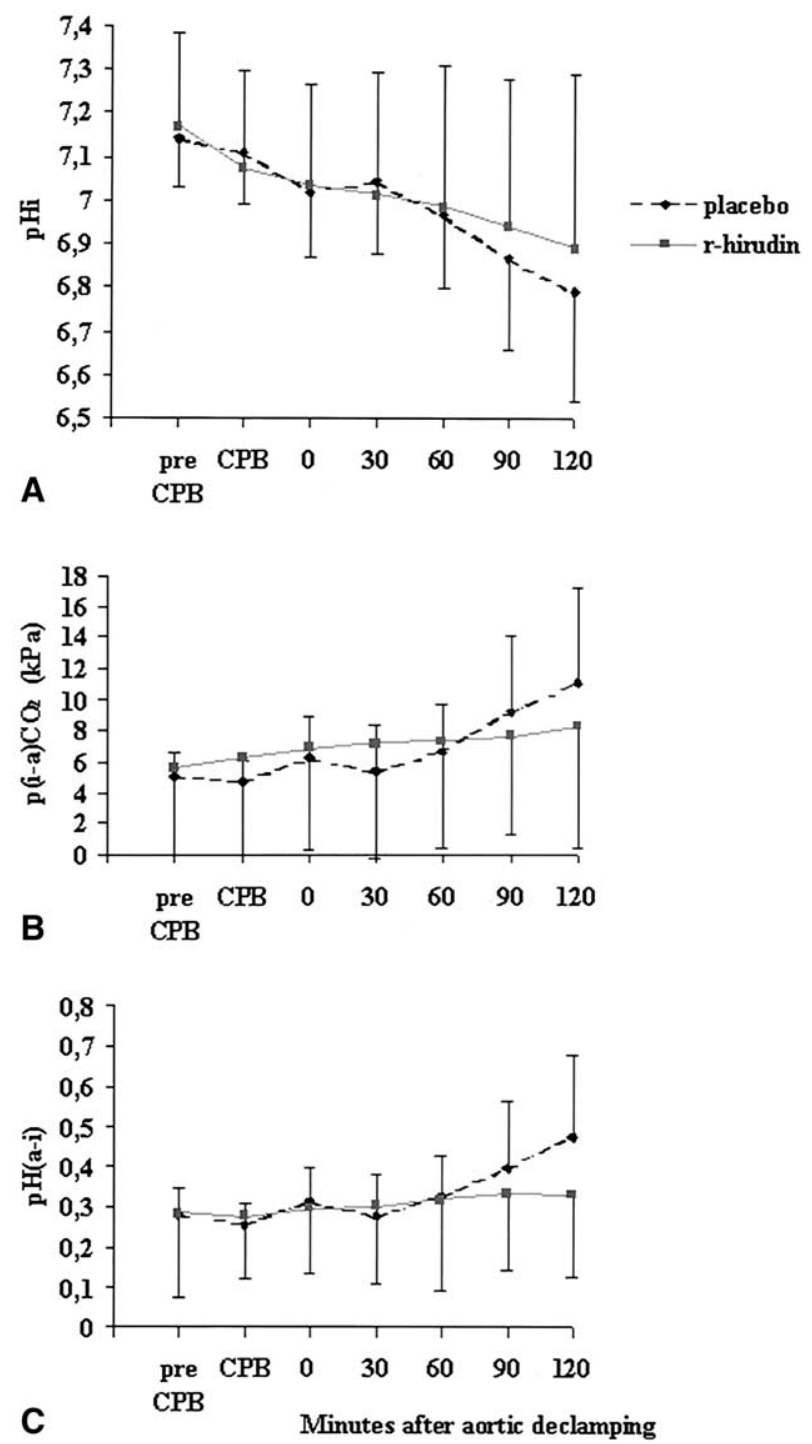

Figure 3. Intestinal $\mathrm{pH}(\mathrm{pHi})(\mathrm{A})$ and the gradients for $\mathrm{PcO}_{2}[\mathrm{P}(\mathrm{i}-$ a) $\mathrm{CO}_{2}$ ] (B) and $\mathrm{pH}[\mathrm{pH}(\mathrm{a}-\mathrm{i})]$ (C) between arterial and intestinal values during $C P B$ and during reperfusion. A significant decrease during CPB and during reperfusion in pHi was seen over time $(P$ $<.001$, analysis of covariance) but no intergroup differences were observed. Of note, a change in the curve trends of crossmucosal $\mathrm{PCO}_{2}$ and $\mathrm{pH}$ gradients at 30 minutes after aortic declamping was observed in the placebo group but not in the r-hirudin group. None of the intergroup differences were statistically significant. Values are given as mean \pm SD. Pre CPB, Before CPB; $C P B, 30$ minutes after the start of $C P B ; 0$, just before aortic declamping.

intestinal perfusion should be based on the gap between arterial and intestinal $\mathrm{PCO}_{2}$ rather than on the intramucosal $\mathrm{pH}$ alone. ${ }^{30-32}$ In our tonometric measurements the gap between the intestinal and arterial $\mathrm{PCO}_{2}$ indicated severe splanchnic hypoperfusion. In the previous studies pHi fell 
TABLE 2. Arterial gas analysis

\begin{tabular}{|c|c|c|c|c|c|c|c|}
\hline \multirow[b]{2}{*}{ Parameter } & \multicolumn{7}{|c|}{ Time after aortic declamping } \\
\hline & Pre-CPB & CPB & 0 minutes & 30 minutes & 60 minutes & 90 minutes & $\begin{array}{c}120 \\
\text { minutes }\end{array}$ \\
\hline \multicolumn{8}{|l|}{$\mathrm{pHa}$} \\
\hline Hirudin & $7.45 \pm 0.08$ & $7.35 \pm 0.09$ & $7.33 \pm 0.08$ & $7.31 \pm 0.10$ & $7.30 \pm 0.12$ & $7.27 \pm 0.17$ & $7.22 \pm 0.2$ \\
\hline Placebo & $7.42 \pm 0.06$ & $7.36 \pm 0.09$ & $7.33 \pm 0.10$ & $7.32 \pm 0.08$ & $7.28 \pm 0.08$ & $7.27 \pm 0.08$ & $7.26 \pm 0.1$ \\
\hline$P$ value & $>.2$ & $>.2$ & $>.2$ & $>.2$ & $>.2$ & $>.2$ & $>.2$ \\
\hline \multicolumn{8}{|l|}{$\mathrm{PaO}_{2}(\mathrm{kPa})$} \\
\hline Hirudin & $25.4 \pm 7.0$ & $45.5 \pm 10.7$ & $44.5 \pm 8.5$ & $20.0 \pm 7.1$ & $18.7 \pm 6.9$ & $19.3 \pm 6.3$ & $18.8 \pm 9.2$ \\
\hline Placebo & $24.6 \pm 6.9$ & $46.1 \pm 13.2$ & $40.5 \pm 11.7$ & $18.5 \pm 7.5$ & $16.0 \pm 2.3$ & $14.4 \pm 3.8$ & $16.9 \pm 5.4$ \\
\hline$P$ value & $>.2$ & $>.2$ & $>.2$ & $>.2$ & $>.2$ & $>.2$ & $>.2$ \\
\hline \multicolumn{8}{|l|}{$\mathrm{PaCO}_{2}(\mathrm{kPa})$} \\
\hline Hirudin & $5.2 \pm 1.1$ & $5.6 \pm 0.5$ & $5.8 \pm 0.4$ & $5.6 \pm 0.6$ & $5.5 \pm 0.5$ & $5.7 \pm 0.7$ & $5.9 \pm 1.1$ \\
\hline Placebo & $5.4 \pm 0.3$ & $5.5 \pm 0.6$ & $5.7 \pm 0.6$ & $5.7 \pm 0.4$ & $5.8 \pm 0.7$ & $5.6 \pm 0.8$ & $5.2 \pm 1.3$ \\
\hline$P$ value & $>.2$ & $>.2$ & $>.2$ & $>.2$ & $>.2$ & $>.2$ & .11 \\
\hline \multicolumn{8}{|l|}{$\mathrm{Hb}(\mathrm{g} / \mathrm{L})$} \\
\hline Hirudin & $83 \pm 11$ & $59 \pm 11$ & $65 \pm 13$ & $67 \pm 12$ & $60 \pm 11$ & $53 \pm 13$ & $46 \pm 16$ \\
\hline Placebo & $87 \pm 14$ & $70 \pm 9$ & $75 \pm 9$ & $72 \pm 8$ & $71 \pm 12$ & $68 \pm 14$ & $63 \pm 18$ \\
\hline$P$ value & $>.2$ & .08 & .14 & $>.2$ & .03 & .006 & .003 \\
\hline
\end{tabular}

Pre-CPB, Before cardiopulmonary bypass ( $P$ value was calculated with Student $t$ test); $C P B$, during cardiopulmonary bypass.

$P$ value for comparison between the 2 experimental groups was calculated with analysis of covariance.

during $\mathrm{CPB}$ but after $\mathrm{CPB}$ pHi was relatively constant or slowly began to return back to baseline values. ${ }^{4,6}$ In contrast, we observed a progressive mucosal acidosis throughout the follow-up. One possible explanation is bleeding seen in both groups, resulting in decrease in hemoglobin and relative hypovolemia, which has been shown to induce splanchnic vasoconstriction and redistribution of the peripheral blood flow. ${ }^{33}$ It has also been shown that during progressive hemorrhage regional critical hypoperfusion in the gut (ie, inadequate oxygen supply to meet tissue requirements and subsequent metabolic acidosis) develops before whole-body perfusion is compromised. ${ }^{34}$ This is consistent with our observation that although during reperfusion hemodynamics were well compensated, hypoperfusion of the gut occurred.

Although r-hirudin evidently did not protect the animals from intestinal hypoperfusion, significant beneficial effect could still be demonstrated when compared with the control animals. The increasing difference between arterial and intestinal $\mathrm{pH}$ during 30 to 120 minutes of reperfusion indicates that microcapillary perfusion significantly deteriorated in the placebo group while in the r-hirudin group this phenomenon was not observed. This effect was probably mostly due to an enhanced cardiac output seen in the rhirudin group. In addition, since low hemoglobin reduces oxygen transport and there was a hemoglobin difference in favor of the control group, the significance of $\mathrm{CO}$ may further increase.

Although r-hirudin has proven to be a safe and effective anticoagulant in patients undergoing $\mathrm{CPB}$, difficulties in monitoring, rather long half-life, possible enhanced bleed- ing tendency, and lack of specific antidote are clear disadvantages of its use in clinical practice. Therefore the current positive hemodynamic effects of r-hirudin should be taken as demonstration of potential of improved control of thrombin rather than a practical solution for the problem. Specifically, no recommendation for human use of hirudin combined with heparin can be derived from the current study. Further studies are being conducted to test whether other thrombin modulators might have the same beneficial effect with less bleeding.

R-hirudin directly inhibits the active site pocket and fibrinogen binding site of free and clot-bound thrombin..$^{35,36}$ R-hirudin, in relative difference to heparin, primarily inhibits thrombin activity instead of thrombin generation. ${ }^{37,38}$ However, thrombin activates several clotting factors and amplifies its own formation. Thus, blocking thrombin activity by r-hirudin might secondarily inhibit further thrombin formation. ${ }^{17}$ Accordingly, in our ischemia-reperfusion model, direct thrombin inhibition throughout the drug infusion was evidenced by highly prolonged ACT values in the r-hirudin group. Instead, a statistically significant difference in the TAT levels developed only at 120 minutes after aortic declamping when the animals in the placebo group showed rapid escalation of thrombin formation but animals receiving r-hirudin did not. Although the more extensive hemodilution in the r-hirudin group may have contributed to the observed difference in TAT concentration, the data suggest that r-hirudin may be an effective inhibitor of reperfusioninduced thrombin formation in addition to being a direct inhibitor of preformed thrombin. 
In conclusion, infusion of thrombin inhibitor r-hirudin during reperfusion was associated with attenuated postischemia left ventricular dysfunction and decreased vascular resistance. Further studies are needed to clarify whether these phenomena were extensively thrombin-related or involved other, yet unidentified secondary effects of r-hirudin. Overall, however, the results suggest that control of coagulation at the level of thrombin activity during ischemiareperfusion injury may potentially improve oxygen delivery to reperfused vascular beds.

We gratefully acknowledge the expert technical assistance by Janette Sintonen.

\section{References}

1. Boyle EM, Pohlman TH, Johnson MC, Verrier ED. The systemic inflammatory response. Ann Thorac Surg. 1997;64:S31-7.

2. Cremer J, Martin M, Redl H, Bahrami S, Abraham C, Graeter T, et al. Systemic inflammatory response after cardiac operations. Ann Thorac Surg. 1996;61:1714-20.

3. Czerny M, Baumer H, Kilo J, Lassnigg A, Hamwi A, Vukovich T, et al. Inflammatory response and myocardial injury following coronary artery bypass grafting with and without cardiopulmonary bypass. Eur J Cardiothorac Surg. 2000;17:727-42.

4. Ohri SK, Becket J, Brannan J, Keogh BE, Taylor KM. Effects of cardiopulmonary bypass on gut blood flow, oxygen utilization, and intramucosal pH. Ann Thorac Surg. 1994;57:1193-9.

5. Ohri SK, Somasundaram S, Koak Y, Macpherson A, Keogh BE, Taylor KM, et al. The effect of intestinal hypoperfusion on intestinal absorption and permeability during cardiopulmonary bypass. Gastroenterology. 1994;106:318-23.

6. Stamler A, Wang H, Weintraub RM, Hariawala MD, Fink MP, Johnson RG. Low-dose dopexamine's effect on lung and gut function after CPB in a sheep model. J Surg Res. 1998;74:165-72.

7. Kirklin JK. Prospects for understanding and eliminating the deleterious effects of cardiopulmonary bypass. Ann Thorac Surg. 1991;51: 529-31.

8. Valen G, Paulsson G, Vaage J. Induction of inflammatory mediators during reperfusion of the human heart. Ann Thorac Surg. 2001;71: 226-32.

9. Kobayashi Y, Yoshimura N, Nakamura K, Yamagishi H, Oka T. Expression of tissue factor in hepatic ischemia-reperfusion injury of the rat. Transplantation. 1998;66:708-16.

10. Armaganian L, Kam G, Eisenberg PR, Schechtman KB, Abendschein DR. Role of tissue factor-mediated injury of Langendorf-perfused rabbit hearts. Coron Artery Dis. 2000;11:581-7.

11. Boyle EM, Pohlman TH, Cornejo CJ, Verrier ED. Endothelial cell injury in cardiovascular surgery: ischemia-reperfusion. Ann Thorac Surg. 1996;62:1868-75.

12. Pober JS, Cotran RS. Cytokines and endothelial cell biology. Physiol Rev. 1990;70:427-51

13. Boisclair MD, Lane DA, Philippou H, Esnouf MP, Sheikh S, Hunt B, et al. Mechanisms of thrombin generation during surgery and cardiopulmonary bypass. Blood. 1993;82:3350-7.

14. De Somer F, Van Bellegham Y, Caes F, Francois K, Van Overbeke H, Arnout J, et al. Tissue factor as the main activator of the coagulation system during cardiopulmonary bypass. J Thorac Cardiovasc Surg. 2002;123:951-8

15. Esmon CT. Introduction: are natural anticoagulants candidates for modulating the inflammatory response to endotoxin? Blood. 2000;95: 1113-6.

16. Esmon CT, Taylor FB, Snow TR. Inflammation and coagulation: linked processes potentially regulated through a common pathway mediated by protein C. Thromb Haemost. 1991;66:160-5.

17. Pernerstorfer T, Hollenstein U, Hansen JB, Stohlawetz P, Eichler HG, Handler S, et al. Lepirudin blunts endotoxin induced coagulation activation. Blood. 2000;95:1729-34.
18. Pearson JM, Schultze AE, Schwartz KA, Scott MA, Davis JM, Roth RA. The thrombin inhibitor, hirudin, attenuates lipopolysaccharideinduced liver injury in rat. J Pharmacol Exp Ther. 1996;278:378-83.

19. Munoz MC, Montes R, Hermida J, Orbe J, Paramo JA, Rocha E. Effect of the administration of recombinant hirudin and/or tissue plasminogen activator (t-PA) on endotoxin induced disseminated intravascular coagulation model in rabbits. Br J Haematol. 1999;105:117-22.

20. Bashore TM, Harrison JK, Davidson CJ. Cardiac catheterization, angiography, and interventional techniques in valvular and congenital heart disease. In: Sabiston DC, Spencer FC, editors. Surgery of the chest. Philadelphia: W. B. Saunders Co; 1995. p. 1133.

21. De Hert SG, Rodrigus IE, Heanen LR, De Mulder PA, Gillebert TC. Recovery of systolic and diastolic left ventricular function early after cardiopulmonary bypass. Anesthesiology. 1996;85:1063-75.

22. Chong AJ, Pohlman TH, Hampton CR, Shimamoto A, Mackman N, Verrier ED. Tissue factor and thrombin mediate myocardial ischemiareperfusion injury. Ann Thorac Surg. 2003;75:S649-55.

23. Hird RB, Crawford FA Jr, Mukherjee R, Spinale FG. Direct effects of thrombin on myocyte contractile function. Ann Thorac Surg. 1995;59: 288-93.

24. Ostrvosky L, Woodman RC, Payne D, Teoh D, Kubes P. Antithrombin III prevents and rapidly reverses leukocyte recruitment in ischemia/ reperfusion. Circulation. 1997;96:2302-10.

25. Özden A, Tetik C, Bilgihan A, Calli N, Bostanci B, Yis Ö, et al. Antithrombin III prevents 60 min warm intestinal ischemia reperfusion injury in rats. Res Exp Med (Berl). 1999;198:237-46.

26. Andersen LW, Landow L, Baek L, Jansen E, Baker S. Association between gastric intramucosal $\mathrm{pH}$ and splanchnic endotoxin, antibody to endotoxin, and tumor necrosis factor- $\alpha$ concentrations in patients undergoing cardiopulmonary bypass. Crit Care Med. 1993;21:210-7.

27. Sinclair DG, Haslam PL, Quinlan GJ, Pepper JR, Evans TW. The effect of cardiopulmonary bypass on intestinal and pulmonary endothelial permeability. Chest. 1995;108:718-24.

28. Granger ND. Role of xanthine oxidase and granulocytes in ischemiareperfusion injury. Am J Physiol. 1988;24:H1269-75.

29. Fiddian-Greene RG. Assessment of the adequacy of mucosal oxygenation in patients with intraluminally located silicone tonometers. In: Manabe H, Zweifach BW, Messmer K, editors. Microcirculation in circulatory disorders. New York: Springer-Verlag; 1988. p. 481-7.

30. Vincent JL, Creteur J. Gastric mucosal pH is definitely obsoleteplease tell us more about gastric mucosal $\mathrm{PCO}_{2}$. Crit Care Med. 1998:26:1479-81.

31. Knichwitz G, Rotker J, Mollhoff T, Richter KD, Brussel T. Continuous intramucosal $\mathrm{pCO}_{2}$ measurement allows the early detection of intestinal malperfusion. Crit Care Med. 1998;26:1550-7.

32. Heino A, Hartikainen J, Merasto ME, Alhava E, Takala J. Systemic and regional $\mathrm{pCO}_{2}$ gradients as markers of intestinal ischemia. Intensive Care Med. 1998;24:599-604.

33. Edouard AR, Degremont A-C, Duranteau J, Pussard E, Berdeaux A, Samii K. Heterogeneous regional vascular responses to simulated transient hypovolemia in man. Intensive Care Med. 1994;20:414-20.

34. Guzman JA, Lacoma FJ, Kruse JA. Relationship between systemic oxygen supply and gastric intramucosal $\mathrm{PCO}_{2}$ during progressive hemorrhage. J Trauma. 1998;44:696-700.

35. Weitz JI, Huboba M, Massel D, Maraganore J, Hirsh J. Clot-bound thrombin is protected from inhibition by heparin-antithrombin III but is susceptible to inactivation by antithrombin III- independent inhibitors. J Clin Invest. 1990;86:385-91.

36. Weitz JI, Leslie B, Huboba M. Thrombin binds to soluble fibrin degradation products where it is protected from inhibition by heparinantithrombin but susceptible to inactivation by antithrombin-independent inhibitors. Circulation. 1998;97:544-52.

37. Eichinger S, Wolzt M, Schneider B, Nieszpaur-Los M, Heinrichs H, Lechner K, et al. Effects of recombinant hirudin (r-hirudin, HBW 023) on coagulation and platelet activation in vivo: comparison with unfractionated heparin and a low-molecular- weight heparin preparation (fragmin). Arterioscler Thromb Vasc Biol. 1995;15:886-92.

38. Zoldehyi P, Bichler J, Owen WG, Grill DE, Fuster V, Mruk JS, et al. Persistent thrombin generation in humans during specific thrombin inhibition with hirudin. Circulation. 1994;90:2671-8. 